\title{
Research of the Evaluation Index System of Green Port Based on Analysis Approach of Attribute Coordinate
}

\author{
Xueyan DUAN ${ }^{1}$, Xiaolin XU ${ }^{2}$, Jiali FENG ${ }^{3}$ \\ ${ }^{1}$ Department of Economic and Management ,Shanghai Polytechnic University, \\ 201209,Shanghai, China; ${ }^{2}$ Department of Electronics and Information, Shanghai Polytechnic \\ University, 201209, Shanghai, China; ${ }^{3}$ Information Engineering College, Shanghai Maritime \\ University, 201306,Shanghai, China \\ ${ }^{1}$ xyduan@sspu.edu.cn; 2 xlxu@sspu.edu.cn; $3 j l f e n g @ 189 . c n$
}

\begin{abstract}
With the coming of low-carbon era the concept of green port becomes more and more important due to the occurrence of abnormal global environmental change. Founded on the previous literatures, the Analysis Approach of Attribute Coordinate is used to analyze evaluation of green port. An index system including three attributes and ten factors is put forwarded. The quantification methods of different indicators are also proposed according to the different property and scoring methods of indicators. The green port evaluation index system can be used to evaluate the port's green operation performance. It is also a good instrument to construct a green port operation for decision makers of port organizations.
\end{abstract}

Keywords: green port; Analysis Approach of Attribute Coordinate; index system; quantification methods

\section{$1 \quad$ Introduction and Literature review}

Port is an important infrastructure and strategic resource in the economic and social development. In the low-carbon economy era Green Port development has become the important field of sustainable development in the world transportation today. How to boost port service capabilities, as well as achieve green sustainable development, has important strategic significance for each port. During green port development, science evaluation and policy guidance is the key point.

In recent years, the domestic and foreign scholars have carried out a large number of research on green port evaluation.

Stone $(1975)^{[1]}$ studies environmental pollution problems in port construction.

Knight(1983) ${ }^{[2]}$,Brooke(1990) ${ }^{[3]}$ and Peris-Moraa E. etc.(2005) ${ }^{[4]}$ build the evaluation index system of port based on the concept of green and ecological.

Shao etc.(2009) ${ }^{[5]}$ establishes ecological port evaluation index system based on Driver-Pressure-State-Impact-Response (DPSIR) model.

$\mathrm{Ge}(2008)^{[6]}$ builds a comprehensive evaluation index system of ecological port.

$\operatorname{Ling}(2010){ }^{[7]}$ introduces the evaluation index system of green port taking Shanghai port as an example. 
Essence(2014) ${ }^{[8]}$ analyses factors and performance of green port and put forward an index system including five dimensions and thirteen factors based on Fuzzy AHP model.

Ouyang(2016) ${ }^{[9]}$ discusses the connotation and features of green and low-carbon port and establishes an evaluation index system including four categories of indexes.

However existing studies somewhat have some difficulties in indicator scoring and do not take the experts' psychological preferences and evaluation process into account. The Analysis Approach of Attribute Coordinate can make up for this deficiency. Therefore, this article attempts to construct a green port evaluation index system based on the Analysis Approach of Attribute Coordinate in order to provide research ideas for related research.

\section{Analysis Approach of Attribute Coordinate}

According to the Attribute Theory, everything that exists objectively has two kinds of stipulation: quality and quantity. Therefore, the attributes of things also have two characteristic values of quantity and quality. The sensory feature extraction system is a converter that transforms the quantitative characteristics $x$ of sensory attributes $a(o)$ into their corresponding quality characteristics $p(x, o)$. The Attribute Theory calls this process Qualitative Mapping(QM). Conversely, it is Converse Qualitative Mapping(CQM) (See as Fig.1). The definition of QM and CQM can be extended from 1 dimension to $n$ dimension.

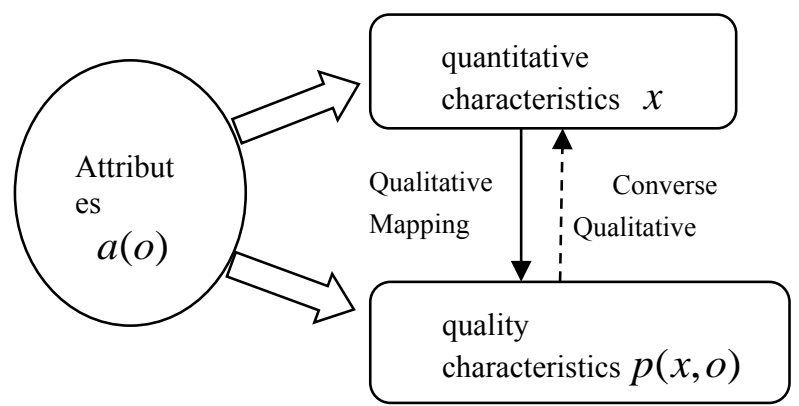

Fig. 1. QM and CQM model of Attribute Theory

For human assessment and decision making, different decision attributes have different decision weights (or preferences). An evaluation and decision model called Analysis Approach of Attribute Coordinate is proposed ${ }^{[11]}$. The Analysis Approach of Attribute Coordinate reflects the psychological standard of the decision-maker and the process of evaluating. It considers the evaluation criteria for nonlinear problems. The nonlinear change of judgment criterion is tracked dynamically by human-computer interaction in order to make appropriate evaluation decisions. It is more consistent with the nonlinear characteristics of human decision-making process.

Meanwhile the Analysis Approach of Attribute Coordinate defines a mental weight which is easier to express psychological preference of decision makers. The meaning of mental weight is the score of corresponding decision attributes when total score equals a certain value. The psychological weight is directly linked to the psychological 
preference of the decision maker, and the distribution is the most reasonable or satisfactory when corresponding to the mental weight of the decision maker.

In recent years the Analysis Approach of Attribute Coordinate is applied to the emergency decision-making evaluation system of college entrance examination ${ }^{[12]}$, the evaluation of third-party logistics enterprises ${ }^{[13]}$, the evaluation of Chinese Software Enterprises ${ }^{[14]}$ and the evaluation of bullwhip effect in supply chain ${ }^{[15]}$.These applications have achieved very good results.

\section{$3 \quad$ Attribute characteristics of Green Port}

Green port means the organic combination of port development and ecological environment protection. Through rational utilization of resources, ports can achieve low energy consumption and low pollution, and achieve harmonious and unified development between people and ports and the environment.

On the one hand, ports need to the scientific integration of existing resources and to ensure the improvement of port development speed; on the other hand, ports also need to pay attention to the quality and efficiency of development, low resource consumption, less environmental pollution, growth advantages and scale effect of the road of sustainable development.

As a systematic concept, green port can deepen its understanding of the three attributes of economy, society and environment (See as Fig.2).

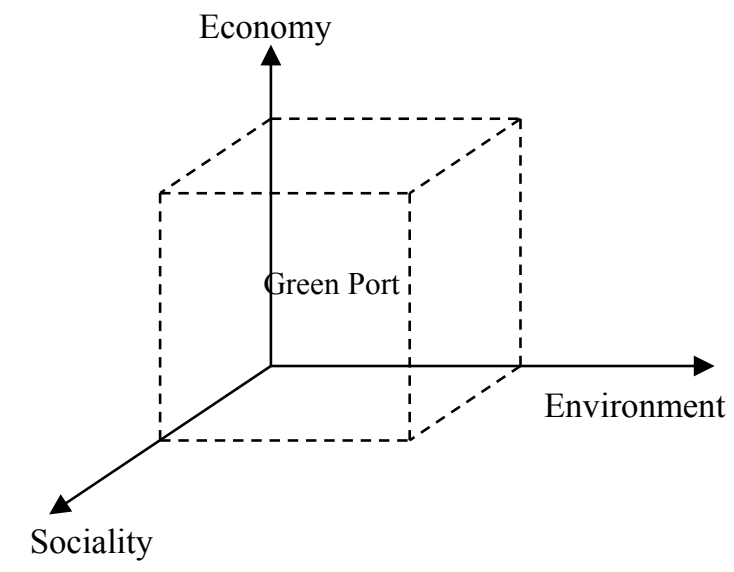

Fig. 2. Three attributes of Green Port

(1) Economic attribute: The economic attribute is the basic index in the evaluation index system of green port, which can fully reflect the economic development level of a port. Green ports also seek an increase in economic returns. The characteristics of port economic benefits can be drawn from the indexes of port GDP, profit and tax ratio, input output ratio, etc.

(2) Society attribute: On the premise of ensuring proper economic development social attribute of port is another important criterion for measuring green ports. The port should be able to play an important role in promoting regional social 
development, promoting the employment of the population in the port area and improving the quality of the population near the port area.

(3) Environment attribute: In essence, the development of green port is resourceefficient and environment-friendly. Resource- efficiency involves conservation of energy, land, coastline and materials, while the environment-friendliness involves objects such as atmosphere, water, sound and ecology.

\section{Evaluation Index System of Green Port}

According to the principles of the index system and the objectives of this study, we establish a recursive hierarchy evaluation index system of attribute coordinate. Evaluation index system of green port is set up including target layer, criterion layer and indicator level. At criterion layer we divide green port system into three dimensions which are economic benefit, social efficiency and ecological environment. Each dimension separately includes several specific indicators. In all there are 10 evaluation indicators.

The index system of green port is shown in Table1.

Table 1. The Evaluation Index System of Green Port

\begin{tabular}{|c|c|c|}
\hline \multirow{3}{*}{$\begin{array}{l}\text { Green Port } \\
\text { (U) }\end{array}$} & $\begin{array}{l}\text { Economical } \\
\text { benefit } \\
(\mathrm{u} 1) \\
\end{array}$ & $\begin{array}{l}\text { Port GDP (u11) } \\
\text { Investment profit rate (u11) } \\
\text { Input-output Ratio }(\mathrm{u} 13)\end{array}$ \\
\hline & $\begin{array}{l}\text { Social } \\
\text { efficiency } \\
\text { (u2) }\end{array}$ & $\begin{array}{l}\text { CargoThroughput（u21） } \\
\text { Passenger Throughput（u22） } \\
\text { Port employment (u23) }\end{array}$ \\
\hline & $\begin{array}{l}\text { Ecological } \\
\text { environment } \\
\text { (u3) }\end{array}$ & $\begin{array}{l}\text { Qualified rate of wastewater discharge (u31) } \\
\text { Air quality qualification rate in harbor area (u32) } \\
\text { Qualified rate of noise pollution in port area (u33) } \\
\text { Green degree of port area (u34) }\end{array}$ \\
\hline
\end{tabular}

\section{Indicator Quantification Method}

In order to carry out the assessment, we must first quantify the 10 indicators of evaluation index system of green port, that means to convert each index value to a standard uniform score. According to Analysis Approach of Attribute Coordinate 100 point system is adopted.

Qualitative indicators are quantified by Converse Qualitative Mapping (CQM).

Let $a(0)$ be an attribute of something (or object). $x$ is a quantity characteristic for $a(0), x \in \mathrm{X} \subseteq \mathrm{R} . \quad p_{i}(0)$ is a quality characteristic for $a(0), p_{i}(0) \in p_{0}$.

$\mathrm{A}=\left(\alpha_{i}, \beta_{i}\right) \in \Gamma$ is qualitative benchmark (or "degree") of $p_{i}(0)$. 
So we call $\mu: X \times \Gamma \rightarrow p_{0}$ is the Qualitative Mapping(QM) of $x$ based on $\left(\alpha_{i}, \beta_{i}\right)$ which can be written into: $\mu: X \times \Gamma \rightarrow\{0,1\}_{i}$,making:

$$
\mu\left(x,\left(\alpha_{i}, \beta_{i}\right)\right)=x \perp\left(\alpha_{i}, \beta_{i}\right)=\mu_{i}(x) .
$$

In consideration of $\left[\alpha_{i}, \beta_{i}\right]$ is a topological neighborhood with $\xi_{i}=\left(\alpha_{i}+\beta_{i}\right) / 2$ as the center and $\delta_{i}=\left(\beta_{i}-\alpha_{i}\right) / 2$ as the radius, the QM can also be written into: $\mu: X \times \Gamma \rightarrow\{0,1\}_{i}$, making :

$$
\mu\left(x, N\left(\xi_{i}, \delta_{i}\right)\right)=x \perp N\left(\xi_{i}, \delta_{i}\right)=\mu_{i}(x) .
$$

Then some qualitative mappings that can be transformed to the Converse Qualitative Mapping (CQM) can be written.

When an expert evaluates a qualitative indicator, the evaluation results are divided into four grades which correspond to four ranges of scores. "Excellent" corresponds to [90-100], "Good " corresponds to [80-90], "General" corresponds to [60-80] and "Inferior" corresponds to [0-60]. Meanwhile experts also need to give the degree of evaluation to the extent of the range.

If the evaluation results are "excellent", "good" and "general", Formula(1) is used to obtain the quantization results.

$$
x\left(\mu_{i}\right)=\beta_{i}+\delta_{i}\left(\mu_{i}-1\right)
$$

If the evaluation results are "Inferior", Formula (2) is used to obtain the quantization results.

$$
x\left(\mu_{i}\right)=\alpha_{i}+\delta_{i}\left(1-\mu_{i}\right)
$$

The quantitative indicators that are percentage are quantified by linear interpolation. If the indicator are positive when the index value is bigger it is the better, Formula (3) is used to obtain the quantization results.

$$
p=f(i)+\frac{f(j)-f(i)}{j-i}[x-f(i)]
$$

If the indicator are negative when the index value is smaller it is the better,, Formula (4) is used to obtain the quantization results.

$$
p=f(j)+\frac{f(j)-f(i)}{j-i}[x-f(j)]
$$

The Indicator Property and Quantification Method are shown in Table 2. 
Table 2. Indicator Property and Quantification Method

\begin{tabular}{c|c|c}
\hline Indicator & Property & Quantification Method \\
\hline U11 & Positive & expert evaluation \\
\hline U12 & Positive & Linear interpolation method \\
\hline U13 & Negative & Linear interpolation method \\
\hline U21 & Positive & expert evaluation \\
\hline U22 & Positive & expert evaluation \\
\hline U23 & Positive & expert evaluation \\
\hline U31 & Positive & Linear interpolation method \\
\hline U32 & Positive & Linear interpolation method \\
\hline U33 & Positive & Linear interpolation method \\
\hline U34 & Positive & Linear interpolation method \\
\hline & &
\end{tabular}

\section{Conclusion}

Ports play an important role in economic development. The evaluation of green ports is of great significance to the development of the world ports. Based on the Analysis Approach of Attribute Coordinate, economic attributes, social attributes and environmental attributes of green port is deeply analyzed. The evaluation index system of the green port is constructed and the corresponding indicator properties and quantization method are put forward. The index system of green ports can be applied to the objective evaluation of the current situation of the development of green ports, so as to guide and promote the construction and development of green ports all over the world. In the follow-up research, the index system can be used in the evaluation of specific ports, and the practical research can also be improved on the basis of the characteristics of the development trend of green ports.

\section{References}

1. Stone J H.:Environmental Impact of a Super port in the Gulf of Mexieo. Inst. Chem. Engineers Publ,Water75:1217-1229.(1975)

2. Knight K D.:Conceptual Ecological Modeling and Interaction Matrices as Environmental Assessment Tools in Coastal Planning. Water Science and Technology,16(3-4):559-567 (1983)

3. Brooke J.:Environmental Appraisal for Ports and Harbours. Doek \& Harbou Authority, 71(820):89-94 (1990)

4. Peris-Mora E, orejas J M D:Subirats Aetal. Development of a System of Indicators for Sustainable Port Management. Marine Pollution Bulletin, 50(12):1649-166 (2005)

5. Chaofeng SHAO, Meiting JU, Ying HE, Xin SUN.:Study on index system of eco-ports based on DPSIR model. Marine Environmental Science, 28 (3) :333-337 (2009)(in Chinese)

6. Zhenming GE, Xiao ZHOU, Jianmin CHENG, Banglin CHEN,Tianhou WANG,Kaiyun WANG.:Preliminary Study on the Comprehensive Evaluation Index System for Ecological 
Ports---Shanghai Port as the example. Resources and Environment in the Yangtze Basin,(03):329-335 (2008) (in Chinese)

7. Qiang Ling:The Preliminary Study of Evaluation Index System for the Shanghai Green Port. Science \& Technology of Ports,(1) :4-7(2010)(in Chinese)

8. Essence I, Citizenship A G.:Evaluation of Green Port Factors and Performance: A Fuzzy AHP Analysis,Mathematical Problems in Engineering, (5):1-12.(2014)

9. Bin OUYANG, Lin WANG, Jingdong HUANG,Aiying GAO: Research and Application of Green and Low-carbon Port Evaluation Index System.Port \& Waterway Engineering (4):7380(2015)(in Chinese)

10.Yue YIN, Qingnian ZHANG:Study on Construction Level Evaluation of Ecological Ports Based on D-S Evidence Theory,Logistics Technology, 35(3):50-54. (2016)(in Chinese)

11.Qinpan WU,Jiali FENG, Zhanqiu DONG,Yongxing ZHANG: A Kind of Evaluation and Decision Model Based on Analysis and Learning of Attribute Coordinate,Journal of Nanjing University(Natural Sciences),39(2):182-188 (2003) (in Chinese)

12.Xiaolan XIE, Jianhua LIU, Qirong LU:Admissions decisions in the university entrance exam system,Journal of Guilin Engineering, 21(4):402-406(2001) (in Chinese)

13.Xueyan DUAN,Yongchang LIU,Guanglin XU,Evaluation on 3PL's core competence based on method of attribute theory,Journal of Shanghai Maritime University,27(1):41-43(2006) (in Chinese)

14.Guanglin XU,Yongchang LIU,Jiali FENG.Evaluation of Chinese Software Enterprises' Core Competence in Attribute Theory,Journal of Guangxi Normal University(Natural Science Edition), 2006, 24(4):34-37(2006)

15.Jianli LI, Yongchang LIU,Jiali FENG:Comprehensive Assessment \& Optimized Selection of Supplier in SCM Based on Attribute Theory, Logistics Technology,26(5):75-79. (2007)(in Chinese) 